\title{
Effect of Gabapentin on Sleep and Event-related Oscillations (EROs) in rats exposed to chronic intermittent ethanol vapor and protracted withdrawal
}

\author{
Manuel Sanchez-Alavez, PhDa , Derek N Wills, BS ${ }^{\mathrm{a}}$, Leslie Amodeo, PhDa, and Cindy L \\ Ehlers, PhDa \\ aDepartment of Neurosciences, The Scripps Research Institute, 10550 North Torrey Pines Road, \\ La Jolla, CA 92037 USA
}

\begin{abstract}
Background-Disturbances in sleep architecture, especially reductions in slow wave sleep (SWS), are symptoms commonly observed in individuals with alcohol use disorders (AUDs). Recent clinical trials have demonstrated that the anticonvulsant and analgesic drug Gabapentin may have therapeutic value in normalizing sleep quality in recovering alcoholics. However, the brain mechanisms underlying this improvement in sleep following Gabapentin treatment remain unknown.
\end{abstract}

Methods-In the present study, adult Wistar rats were exposed to 8 weeks of chronic intermittent ethanol vapor (CIE) (blood ethanol concentrations averaged $128.2 \pm 17.4 \mathrm{mg} / \mathrm{dL}$ ) or control conditions and then withdrawn. Sleep EEGs and event-related oscillations (EROs) were evaluated at baseline prior to ethanol exposure and 24 hours following ethanol withdrawal. Four weeks following ethanol withdrawal the effects of saline and two doses of Gabapentin $(30 \mathrm{mg} / \mathrm{kg}, 120$ $\mathrm{mg} / \mathrm{kg}$ ), on EROs and sleep EEGs, were evaluated.

Results-As compared to baseline, 24 hours following alcohol withdrawal SWS became fragmented as indexed by a significant increase in the number and a decrease in the duration of SWS episodes. Compared to controls, the ethanol exposed group had more ERO energy in the beta frequency band in the parietal cortex. Gabapentin induced a dose dependent decrease in the latency to the first SWS episode, and a reduction in sleep fragmentation. Gabapentin also produced a dose dependent increase in ERO energy in the control group that was significantly attenuated in the ethanol exposed group in the theta, and beta frequency bands.

Conclusions-Taken together these studies suggest that Gabapentin can reverse some of the alcohol- induced sleep and EEG deficits but does not eliminate all of the enduring brain effects of ethanol exposure.

\section{Keywords}

Alcohol; EEG; event related oscillations; Gabapentin; slow wave sleep

Corresponding Author: Cindy L. Ehlers, The Scripps Research Institute, Department of Neurosciences, 10550 North Torrey Pines Road, SP30-1501, La Jolla, CA 92037, Tel: (858) 784-7058; Fax: (858) 784-7409; cindye@ scripps.edu.

DR. MANUEL SANCHEZ-ALAVEZ (Orcid ID: 0000-0002-8164-8452) 


\section{Introduction}

According to the 2015 National Survey on Drug Use and Health (NSDUH), 15.1 million adults age 18 and older (6.2\%), in the United States, had an Alcohol Use Disorder (AUD) (SAMHSA, 2015). Alcohol use disorder is defined by a cluster of psychological, behavioral and physical symptoms, which can include: craving, tolerance, use in dangerous situations and despite harmful consequences, as well as the emergence of a withdrawal syndrome on cessation of use (American Psychiatric Association; DSM-5 Task Force., 2013).

After acute withdrawal, chronic alcohol users may complain of light, fragmented sleep with a deficit in slow-wave sleep that can persist for months and can contribute to relapse (Drummond et al., 1998, Brower and Perron, 2010). Alcohol-induced sleep disorder (insomnia) is one of 8 core criteria in the DSM-5 diagnosis of alcohol withdrawal (American Psychiatric Association; DSM-5 Task Force., 2013), and refers to difficulty initiating or maintaining sleep, or waking earlier than intended and/or non-restorative or poor quality sleep as reported by the patient (Brower, 2015). Insomnia symptoms are distressing to the patient, and can interfere with daytime functioning. They may occur despite adequate opportunity for sleep (American Psychiatric Association; DSM-5 Task Force., 2013) and can compromise the efforts of alcohol dependent patients to initiate and/or maintain sobriety (Conroy et al., 2006), even in the absence of mood disorders (Clark et al., 1998).

Current FDA-approved pharmacologic treatments for insomnia include: benzodiazepines and non-benzodiazepine hypnotics, tricyclic antidepressants, therapeutic drugs that target orexin/hypocretin receptors, and off-label use of drugs such as other antidepressants, antihistamines, herbal preparations and antipsychotics (for guidelines and reviews see (Qaseem et al., 2016, Sateia et al., 2017, Coleman et al., 2017)). However, some agents such as benzodiazepines and other hypnotics, may not be suitable for the treatment of sleep disturbance in alcohol dependence because of their potential for addiction and collateral effects that can include: residual sedation, memory and performance impairment, undesired behaviors during sleep, somatic symptoms, and drug interactions (Mark et al., 2009).

In 1993 Gabapentin (GP), which binds the a $2 \delta$ auxiliary subunit of the voltage-gated calcium channels, was approved by the FDA for the treatment of partial seizures, and later was used in the treatment of a variety of disorders associated with sleep disruption including psychiatric disorders, restless legs syndrome (RLS), periodic limb movement disorder (PLMD), headache, neuropathic pain syndromes, and movement disorders (Magnus, 1999). Gabapentin enhances slow-wave sleep in patients with primary insomnia (Foldvary-Schaefer et al., 2002), improves sleep quality by elevating sleep efficiency and decreasing spontaneous arousals (Lo et al., 2010, Bazil et al., 2005). Additionally, Gabapentin has been demonstrated to improve rates of abstinence, measures of mood, sleep, and craving in alcohol dependent individuals in several clinical trials (Brower, 2015, Brower et al., 2008, Mason et al., 2014).

Despite the clear importance of sleep disturbance in the clinical course of alcoholism and the maintenance of sobriety, the complex mechanisms that underlie alcohol-induced insomnia and suitable therapeutic approaches to its management remain to be fully developed. The 
development of animal models of alcohol-induced insomnia allows for the experimental control necessary to study the effects of ethanol, independent of many factors that confound human studies, such as psychiatric comorbidity and other substance use. It also allows for the exploration of both the mechanisms underlying alcohol-induced insomnia and for the testing of potential therapeutic targets. Studies from our laboratory, and others, in rats, have demonstrated that chronic high-dose ethanol exposure can produce long-term persistent changes in sleep, similar to what is seen in human alcoholics. For instance, adult rats treated with chronic ethanol show: increases in sleep latency, reductions in the mean duration of slow wave sleep (SWS) episodes and the total amount of time spent in SWS (Criado et al., 2008, Ehlers et al., 2013, Ehlers and Slawecki, 2000, Thakkar et al., 2015). Despite the development of these animal models, their use to identify mechanisms underlying alcoholinduced insomnia and to identify therapeutic targets has been limited.

The present study had two specific aims. The first aim was to describe the effects of chronic alcohol exposure on acute alcohol withdrawal using measures of sleep and waking electrophysiology in rats. For the sleep recordings, we employed traditional polysomnography. However, for the waking electrophysiology we used event-related oscillations (EROs). EROs are oscillatory changes within the dynamics of ongoing EEG rhythms that are synchronized or enhanced by a time locked cognitive and/or sensory stimulus (see (Basar et al., 2000, Roach and Mathalon, 2008, Klimesch et al., 2007, Anokhin, 2014)). EROs have been shown to be sensitive measures of normal (Schack and Klimesch, 2002, Basar et al., 1999) and abnormal cognitive functioning, as well as more importantly, specific endophenotypes for alcohol use disorders (Ehlers et al., 2015, Pandey et al., 2012, Rangaswamy and Porjesz, 2014). Therefore, we sought to use these measures to index the effects of chronic alcohol exposure and withdrawal on waking EEG. Our second aim evaluated the potential of Gabapentin to ameliorate the effects of chronic alcohol exposure on sleep and waking EEG. Although Gabapentin has been demonstrated to reduce drinking in an animal model of chronic alcohol vapor exposure (Roberto et al., 2008), its effects on sleep and EROs in this model has not been evaluated. Therefore, we tested the effects of saline and two doses of Gabapentin on sleep and waking EROs in rats chronically exposed to ethanol vapor and withdrawal.

\section{Material and methods}

\section{Animal subjects}

Forty-eight male Wistar rats were obtained from Charles River (USA) and arrived on postnatal day (PD) 90. Rats were pair-housed in standard plastic cages in a temperaturecontrolled room with a $12 \mathrm{~h}$ light/dark cycle. All testing was conducted at the onset of the light cycle, which occurred at 8:00 am. Food and water were available ad libitum. The work described herein adheres to the guidelines stipulated in the NIH Guide for the Care and Use of Laboratory Animals (NIH publication No. 80-23, revised 1996) and was reviewed and approved by The Scripps Research Institute's Animal Care and Use Committee. 


\section{Surgical procedure}

Surgical and electrophysiological recording procedures performed in this study have been previously described (Ehlers et al., 2013, Ehlers and Slawecki, 2000). Rats (PD 112-141) were surgically implanted with screw electrodes in the skull overlying the frontal cortex (FCTX, AP: $1.5 \mathrm{~mm}, \mathrm{ML}: \pm 3.0 \mathrm{~mm}$, FR1), and parietal cortex (AP: $-4.5 \mathrm{~mm}, \mathrm{ML}: \pm 4.5$ $\mathrm{mm}$ ) with a corresponding reference electrode posterior to lambda overlying the cerebellum. Surgical coordinates were obtained from the Paxinos and Watson (Paxinos and Watson, $1986)$ atlas. An electromyography (EMG) wire electrode was inserted into the rats' neck muscle. EEG and EMG electrodes were connected to a multi-pin PlasticsOne ${ }^{\circledR}$ connector and the assembly was anchored to the skull with dental acrylic and anchor screws. Rats were given at least 2 weeks of recovery before EEG recording.

\section{Ethanol vapor exposure}

Ethanol vapor exposure has been shown to reliably allow for the titration of blood ethanol concentrations (BECs) that are sufficient for inducing physical ethanol dependence. The ethanol vapor inhalation procedure and the chambers used in this study were previously described (Slawecki, 2002). Ethanol vapor chambers were calibrated to produce high to moderate BECs between $175-225 \mathrm{mg} / \mathrm{dL}$. In brief, rats $(\mathrm{n}=48)$ were randomly divided into two groups each (Ethanol group, $n=24$; Control group, $n=24$ ). After the baseline recordings, ethanol rats were housed in sealed chambers, infused with vaporized $95 \%$ ethanol from 8 p.m. to 10 a.m. For the remaining $10 \mathrm{hrs}$ of the day, ethanol vapor was not infused into the chambers. Rats were exposed to this vapor cycle for 8 weeks (PD 173-228). Blood samples were collected from the tip of the tail every 3-4 days during the 8-week exposure period to assess BECs (average for 8 weeks $128.2 \pm 17.4$ ). Control animals were handled identically to ethanol rats. BECs were determined using the Analox micro-statAM1 (Analox Instr. Ltd., Lunenberg, MA). Following the 8-week exposure, ethanol animals were transferred to standard polycarbonate cages for the duration of the experiment. Figure 1 shows graphical representation of the timing of the experimental procedure (Figure 1A), the animals' body weights and the average BECs for the ethanol rats (Figure 1B).

\section{Electrophysiological recordings}

After recovery from surgery, rats were habituated to the EEG testing chambers prior to the electrophysiological testing. For waking EROs, animals were placed in individual polycarbonate chambers within a sound and electrically shielded recording chamber. Rats were unrestrained but were spatially restricted. Rats were first presented with auditory stimuli through a small speaker centered approximately $70 \mathrm{~cm}$ above the rat's head. Auditory stimuli and EROs were elicited using an oddball plus "noise" paradigm described previously (Ehlers et al., 2014, Ehlers et al., 2012). Each auditory ERO session consisted of 312 trials that lasted approximately 10 minutes and each trial presented one of three randomly generated tones: standard tone $(84 \%$ probability, $75 \mathrm{db}, 1000 \mathrm{~Hz})$, rare tone $(10 \%$ probability, $85 \mathrm{db}, 2000 \mathrm{~Hz}$ ), or startle tone (6\% probability, $100 \mathrm{db}$, white noise). Individual trials were $1000 \mathrm{~ms}$ in duration ( $200 \mathrm{~ms}$ pre-stimulus $+800 \mathrm{~ms}$ post-stimulus) and the interval between tones varied from $750 \mathrm{~ms}$ to $1500 \mathrm{~ms}$. 
A $5 \mathrm{~h}$ EEG sleep recording occurred about $5 \mathrm{~min}$ after the conclusion of the ERP session. All rats were determined to be awake at the start of each EEG session. Signals were transferred to a PC and digitized at a rate of $256 \mathrm{~Hz}$. The EEG amplifier input range corresponding to the full range of the 12-bit analog-to-digital converter was about $+/-250$ microvolts. Periodic calibration results were used to scale the digitized EEG to microvolts.

Rats were given a baseline electrophysiology session that consisted of an oddball auditory event-related potential (ERP) test during waking, to generate event-related oscillations (EROs) followed by a $5 \mathrm{~h}$ EEG sleep recording prior to ethanol exposure (PD 145-169). A second ERO and $5 \mathrm{~h}$ sleep recording session was conducted $24 \mathrm{~h}$ after withdrawal from the vapor chambers (PD 229-238). Approximately one month after acute alcohol withdrawal, all rats had three additional recording sessions (ERO 5-hr sleep) following the administration of: saline, low (30mg/kg), or high (120 mg/kg) dose Gabapentin (PD 271-300) (described below) prior to the recordings. For all sessions the recordings began at " lights on" at 08:00.

\section{Acute Gabapentin and saline administration}

All rats received their saline (intraperitoneally, IP) as the first of the three injections that were followed by recording sessions. Following the injection, they were placed in the electrophysiological recording chamber and the test session began approximately $15 \mathrm{~min}$ post-injection. Two additional sessions were conducted with a randomized administration of two doses of Gabapentin (Tokyo Chemical Industry Co - TCI): low dose (30 mg/kg) or high dose $(120 \mathrm{mg} / \mathrm{kg})$. These doses were selected as they corresponded to the doses reported previously to produce reductions in drinking as well as to reverse the anxiogenic effects of ethanol abstinence in ethanol vapor exposed rats (Roberto et al., 2008). At least a week was given between doses to avoid carry over effects from the drug. The Gabapentin concentrations were prepared fresh for each day of testing for groups containing three to six rats each, and the saline doses were given in equal frequency and at equivalent volumes to the Gabapentin doses.

\section{Sleep analysis}

Slow-wave sleep (SWS) was visually identified as synchronized slow-wave activity (1-4 $\mathrm{Hz}$ ) during the 5-h EEG recording session that included baseline, $24 \mathrm{hr}$ withdrawal after ethanol vapor or control exposure, saline injection control, Gabapentin $30 \mathrm{mg} / \mathrm{kg}$ and Gabapentin $120 \mathrm{mg} / \mathrm{kg}$. Increases in EEG power of at least twice the amplitude of waking baseline EEG power lasting longer than $8 \mathrm{~s}$ were counted as episodes of SWS. Sleep patterns were analyzed by: 1) determining the onset latency of the first episode of SWS, 2) calculating the mean duration of all episodes of SWS, and 3) counting the total number of instances of SWS. The onset of the first SWS episode was identified from the raw EEG as the first transition from low-amplitude high-frequency EEG to SWS (high-amplitude lowfrequency EEG) and lasting at least $8 \mathrm{~s}$.

\section{Waking EEG analyses of ERO energy}

Data from single trials generated by the ERP stimuli were entered into a time frequency analyses algorithm, $S$-transform (ST), a generalization of the Gabor transform (Stockwell et al., 1996). The S-transform mathematically resembles the continuous wavelet transform but 
it uses Gaussian windows which do not meet a requirement of wavelet analysis, and it includes a "phase correction" that is not part of wavelet analysis. The actual use of the Stransform was simplified by performing first a forward Fourier transform of the time series. Then, for each frequency of the Fourier transform, the results of multiplication were summed by a set of Fourier transforms of Gaussian windows of varying width. Finally, for each of these sums, the inverse of the Fourier transform was taken. The $S$-transform resulted in a time-frequency representation of the data. The exact code we used is a language, $S$ transform subroutine available from the NIMH MEG Core Facility web site (http:// kurage.nimh.nih.gov/meglab/). This code is specifically for use with real time series, so it sets the input imaginary values, required by the $S$-transform, to zero, and it always uses the Hilbert transform so that each of the complex output time series is an analytic signal.

To reduce anomalies in the $S$-transform output at the beginning and the end of the output time series, we used a Hanning window over the initial and final $100 \mathrm{msec}$ of the input time series. The output of the transform for each stimuli and electrode site was calculated by averaging the individual trials containing the time-frequency energy distributions. To quantify $S$-transform magnitudes, a region of interest (ROI) is defined by specifying the band frequencies and time interval dimensions of the rectangular ROI. The time-frequency points saved from each $S$ transformation are from $200 \mathrm{~ms}$ before to $800 \mathrm{~ms}$ after the onset of the stimulus, and from $1 \mathrm{~Hz}$ through $50 \mathrm{~Hz}$ at intervals of $0.5 \mathrm{~Hz}$. Energy is the square of the magnitude of the $S$-transform output in a time frequency region of interest. The $S$-transform output for a time/frequency ROI, for a specific EEG lead, is proportional to the input voltage of the lead over the time/frequency interval. The $S$-transform magnitude squared for a time/ frequency interval is therefore proportional to volts squared. These analyses are similar to what has been previously described (Thatcher, 2012).

Rectangular regions of interest (ROIs) were defined within the time-frequency analysis plane by specifying, for each ROI, a band of frequencies and a time interval relative to the stimulus onset time. Time 0 in these definitions is the onset of the stimulus. The 3 ROIs were: delta band, 1-4 Hz, 200-500 ms, theta band, 4-7 Hz, 10-400 ms, and beta band, 13$30 \mathrm{~Hz}, 0-300 \mathrm{~ms}$. These regions were chosen a priori to coincide with the major EEG frequencies present in the rat and the latency windows of the N1, P3a and P3b event-related potential components in the rat reported previously (Ehlers et al., 2014). Using mean values over trials, the maximum energy values were calculated for each ROI, at each electrode location.

\section{Statistical analyses}

Statistical analyses were performed using SPSS (IBM Corp, Armonk, NY) software to test the two research aims. For aim 1, in order to test the effects of alcohol exposure and withdrawal on sleep and EEG parameters, a 2-way group (EtOH vs control) $\mathrm{X}$ time (baseline vs. 24 hours withdrawal) ANOVA was used. The variables assessed in the analyses for aim 1 were: number of SWS sleep episodes, the onset and duration of the first SWS episode, mean duration of SWS events, and ERO energy in the 3 ROIs to the rare tone in the two leads (Fz, Pz). For aim 2, in order to determine the effect of saline and Gabapentin on the sleep and ERO measures, a 2-way group (EtOH vs. control) X treatment (saline, $30 \mathrm{mg} / \mathrm{kg}, 120 \mathrm{mg} / \mathrm{kg}$ 
Gabapentin) ANOVA was employed using the same sleep and EEG variables described for aim 1. In both sets of analyses post-hoc analyses were conducted when significant main effects were found. Values are presented as mean \pm standard error of the mean (SEM) and significances were considered at $\mathrm{p}<0.05$. Due to loss of electrode function over time the number of animals in each group differed depending on the condition.

\section{Results}

\section{Effects of chronic EtOH exposure and 24 hours of withdrawal on sleep}

The first research aim concerned the effects of chronic alcohol exposure and 24 hours of withdrawal on sleep and waking electrophysiology in rats. Significant effects were found in sleep measures when baseline prior to ethanol exposure was compared to 24 hours following withdrawal. Repeated measures ANOVA revealed a significant main effect of group on acute alcohol withdrawal in the latency to SWS (group: $\mathrm{F}(1,40)=4.0, \mathrm{p}=0.05$; interaction, $\mathrm{F}(1,40)=9.5, \mathrm{p}=0.004)$. As seen in figure $2 \mathrm{~A}$, post hoc analyses revealed that latency to SWS was reduced in the EtOH exposed group as compared to the control (post hoc: control= $3457.8 \pm 420 \mathrm{sec}$ vs. $\mathrm{EtOH}=1163.6 \pm 473.5 \mathrm{sec}, \mathrm{F}(1,41)=12.9, \mathrm{p}=0.001)$. No significant differences were found between the EtOH and control rats in the duration of the first SWS episode (group effect: control $=69.8 \pm 16.9 \mathrm{sec}$ vs. $\mathrm{EtOH}=69.5 \pm 17.5 \mathrm{sec}, \mathrm{p}=0.9$, figure of 2B). However, a significant main effect of ethanol withdrawal was found in the mean duration of SWS episodes (time: $\mathrm{F}(1,40)=9.3 ; \mathrm{p}=0.004$ ), and in the number of SWS episodes (time: $\mathrm{F}(1,40)=5.0, \mathrm{p}=0.03$; group, $\mathrm{F}(1,40)=9.4, \mathrm{p}=0.004$; group $\mathrm{X}$ time interaction, $\mathrm{F}(1,40)=10.9, \mathrm{p}=0.002)$. Post-hoc analyses revealed that, in the EtOH-exposed group, the number of SWS episodes was markedly increased (control=57.5 \pm 2.3 vs. EtOH=79.6 \pm 4.2 , $\mathrm{F}(1,41)=19.9$, $\mathrm{p}<0.001$, figure $2 \mathrm{C})$, and the mean duration of SWS episodes was reduced (control=100.2 $\pm 7.3 \mathrm{sec}$ vs. $\mathrm{EtOH}=81.6 \pm 5.5, \mathrm{~F}(1,41)=4.2$, $\mathrm{p}<0.05$, figure $2 \mathrm{D})$.

\section{Effects of chronic EtOH exposure and 24 hours of withdrawal on EROs energy}

Chronic ethanol exposure and withdrawal also produced effects on ERO energy in the three frequency bands (delta, theta, beta). Repeated measures ANOVA showed that, compared to their respective baseline, during $24 \mathrm{hr}$ withdrawal, there was a time and time $\mathrm{x}$ group interaction in ERO energy in the delta frequency band in frontal cortex (time: $F(1,37)=46.2$, $\mathrm{p}<0.001$; group $\mathrm{X}$ time interaction: $\mathrm{F}(1,37)=4.7, \mathrm{p}<0.05)$ and in parietal cortex (time: $\mathrm{F}(1,39)=16.0, \mathrm{p}<0.001$; group $\mathrm{x}$ time interaction: $\mathrm{F}(1,39)=5.3, \mathrm{p}<0.05)$. In addition, there was a time effect in the theta (time: $\mathrm{F}(1,37)=13.6, \mathrm{p}=0.001$ ), and beta (time: $\mathrm{F}(1,37)=15.9$, $\mathrm{p}<0.001$ ) frequency bands in frontal cortex and in the beta (time: $\mathrm{F}(1,39)=10.8, \mathrm{p}=0.002$ ) frequency bands in the parietal cortex. Post-hoc analyses revealed a significant increase in EROs energy during withdrawal in the delta (control $=152.7 \pm 19.2$ vs. EtOH= $206.5 \pm 18.8$, $\mathrm{F}(1,40)=4.0, \mathrm{p}=0.05$ ) and beta (control= $232.6 \pm 27.7 \mathrm{vs.} \mathrm{EtOH}=333.4 \pm 28.4, \mathrm{~F}(1,40)=6.4$, $\mathrm{p}=0.02$ ) frequency bands in the EtOH-exposed group in the parietal cortex (Figure 3). Post hocs did not reveal further differences in ERO energy in any frequency band in frontal cortex. 


\section{Effects of saline and Gabapentin on ethanol-induced alterations of sleep}

Our second aim evaluated the potential of Gabapentin to ameliorate the effects of chronic alcohol exposure on sleep and waking EEG observed following alcohol withdrawal. A 2way repeated measures ANOVA, for group (EtOH vs. control) and treatment (saline, 30 $\mathrm{mg} / \mathrm{kg}, 120 \mathrm{mg} / \mathrm{kg}$ ) was used. A main effect of treatment was seen in the number of SWS episodes (treatment: $\mathrm{F}(2,34)=4.5 ; \mathrm{p}=0.03$, figure $2 \mathrm{C}$ ). Post hoc analyses showed that the increase in the number of SWS episodes observed during the acute withdrawal, in the ethanol exposed group, persisted in the saline condition one month following withdrawal (control=39.9 $\pm 3.7 \mathrm{vs.} \mathrm{EtOH}=54.6 \pm 5.0, \mathrm{~F}(1,36)=5.0, \mathrm{p}=0.03$, figure 2C). Gabapentin was found to reduce the number of SWS episodes so that similar levels were seen between the two groups at both the $30 \mathrm{mg} / \mathrm{kg}$ dose (post hoc: control $=44.9 \pm 2.9 \mathrm{vs}$. $\mathrm{EtOH}=49.2 \pm 3.1$, $\mathrm{p}=0.3$ ), and the $120 \mathrm{mg} / \mathrm{kg}$ dose (post hoc: control= $37.2 \pm 2.7 \mathrm{vs.} \mathrm{EtOH}=41.3 \pm 2.5, \mathrm{p}=0.3$ ). Repeated measures ANOVA also showed a treatment effect for the mean duration of SWS episodes (treatment: $\mathrm{F}(2,34)=102 ; \mathrm{p}<0.001$, figure 2D). The reduction in the mean duration of all of the SWS episodes observed during acute withdrawal was also found to persist into the saline condition in the ethanol-exposed group (control=122.4 $\pm 8.6 \mathrm{sec}$ vs. $\mathrm{EtOH}=82.1$ $\pm 6.7 \mathrm{sec}, \mathrm{F}(1,36)=14.1, \mathrm{p}=0.001$, figure 2D). Gabapentin was found to increase the mean duration of all of the SWS episodes bringing the duration of SWS in the EtOH group to similar levels seen the control group at both $30 \mathrm{mg} / \mathrm{kg}$ (post hoc: control=194.1 $\pm 15.5 \mathrm{sec}$ vs. $\mathrm{EtOH}=164.8 \pm 10.0 \mathrm{sec}, \mathrm{p}=0.1$ ), and $120 \mathrm{mg} / \mathrm{kg}$ (post hoc: control= $281.9 \pm 22.4 \mathrm{sec}$ vs. $\mathrm{EtOH}=237.7 \pm 17.1 \mathrm{sec}, \mathrm{p}=0.1$ ). Repeated measures ANOVA showed that Gabapentin caused a dose dependent decrease in the latency to the first SWS episode (treatment: $\mathrm{F}(2,34)=40.3 ; \mathrm{p}<0.001$, figure $2 \mathrm{~A})$ and an increase in the duration of the first SWS episode (treatment: $\mathrm{F}(2,34)=8.4, \mathrm{p}=0.005$, figure $2 \mathrm{~B}$ ) in both groups (control and EtOH exposed group) with no significance differences between the two groups at any dose.

\section{Effects of saline and Gabapentin on EROs energy}

Our second aim also evaluated if the response to saline and Gabapentin, as indexed by waking ERO energy, differed between the control and EtOH-exposed groups in frontal and parietal cortex. Repeated measure ANOVA revealed an effect of treatment (saline, Gabapentin $30 \mathrm{mg} / \mathrm{kg}, 120 \mathrm{mg} / \mathrm{kg}$ ) on ERO energy in delta frequency band in frontal cortex (treatment: $\mathrm{F}(2,34)=7.5, \mathrm{p}=0.001$ ) and parietal cortex (treatment: $\mathrm{F}(2,35)=10.9, \mathrm{p}<0.001$ ) however, post hocs revealed no significant differences between the control and EtOHexposed groups in either cortices (figure 3). In addition, repeated measures ANOVA revealed group, treatment, and group $\mathrm{X}$ treatment interactions in ERO energy in theta (group: $\mathrm{F}(1,35)=5.8, \mathrm{p}=0.02$; treatment: $\mathrm{F}(2,34)=10.9, \mathrm{p}=0.001$; interaction, $\mathrm{F}(2,70)=6.1, \mathrm{p}=0.01)$ frequency band, and dose with dose $x$ group interaction in beta (treatment: $F(2,34)=9.5$, $\mathrm{p}=0.001$; group $\mathrm{X}$ treatment interaction: $\mathrm{F}(2,70)=6.4, \mathrm{p}=0.008)$ frequency band in the frontal cortex. Post hoc ANOVA revealed a significant increase in ERO energy in the control rats, but not in the EtOH rats, in the theta frequency band after injection of Gabapentin $30 \mathrm{mg} / \mathrm{kg}$ (control=912.4 \pm 220.1 vs. $\mathrm{EtOH}=406.0 \pm 36.5, \mathrm{~F}(1,36)=5.4, \mathrm{p}=0.026)$ and further increases in ERO energy in the theta frequencies after injection of Gabapentin $120 \mathrm{mg} / \mathrm{kg}$ (control=1177.7 \pm 268.4 vs. $\mathrm{EtOH}=505.1 \pm 46.6, \mathrm{~F}(1,36)=6.4 \mathrm{p}=0.016$ ), and increases in EROs energy in the beta frequency band after Gabapentin $120 \mathrm{mg} / \mathrm{kg}$ (control= $969.4 \pm 186$ vs. $\mathrm{EtOH}=511.6 \pm 68.6, \mathrm{~F}(1,36)=5.5, \mathrm{p}=0.024)$. 
In the parietal cortex, repeated measure ANOVA revealed a treatment effect and group $X$ treatment interaction in ERO energy in theta (treatment: $\mathrm{F}(2,35)=5.0, \mathrm{p}=0.02$; interaction, $\mathrm{F}(2,72)=3.8, \mathrm{p}=0.04)$ frequency band and a treatment effect in beta frequency band (treatment: $\mathrm{F}(2,35)=5.2, \mathrm{p}=0.01)$. Post hoc ANOVA revealed a significant increase in ERO energy in the theta frequency band for the control rats, but not for the EtOH rats, following injection of Gabapentin $120 \mathrm{mg} / \mathrm{kg}$ (control=905.5 \pm 184.3 vs EtOH $544.5 \pm 43.0$, $\mathrm{F}(1,37)=4.4, \mathrm{p}=0.04)$. Post hoc revealed no significant difference between groups on ERO energy in beta frequency band (Figure 3).

\section{Discussion}

During chronic alcohol exposure, key neurobiological mechanisms underlying the homeostatic regulation of sleep and arousal become dysregulated. This dysregulation results in a protracted alcohol "withdrawal-like state" that includes changes in affective and motivational behaviors as well as changes in sleep (Ehlers and Slawecki, 2000). We have shown that there is a critical length of time necessary for an animal to be exposed to alcohol vapor in order to induce neuroadaptive changes in both behavior and neurochemistry that persist into protracted withdrawal (Walker et al., 2010) which is between 6-8 weeks of vapor exposure. One of those neuroadaptative changes involves sleep pathology. Here we show that after chronic alcohol exposure SWS became fragmented during withdrawal as indexed by a significant increase in the number of SWS episodes and significant decrease in the duration of each episode. This finding is particularly important because it correlates with our epidemiological study in human populations where alcohol-use disorders are significantly associated with poorer quality of sleep in young adults (Ehlers et al., 2010).

Alcohol withdrawal was also found to influence waking EEG activity as indexed by EROs. Twenty-four hours following withdrawal from the vapor or control chambers, ethanolexposed rats had significantly increased ERO energy in beta frequency band in the parietal cortex with no other evident changes in any other frequency or region. These studies are also complementary to studies in human subjects where increased beta activity has been reported in many studies in human alcoholics during waking and sleep (see (Bauer, 2001, Fein and Allen, 2005, Porjesz et al., 2005, Rangaswamy et al., 2002, Irwin et al., 2000)). EEG beta has been suggested to represent a sign of neural excitability or "disinhibition" when seen in alcoholics (Porjesz et al., 2005). It has also been demonstrated to be a good endophenotype in genetic studies of families with alcohol use disorders (Meyers et al., 2017, Porjesz et al., 2002). Taken together these studies suggest that beta EEG/ERO activity may be an important biomarker that could potentially be used to unravel the mechanisms underlying alcohol use disorder as well as provide a target for therapeutics.

Despite the abundance of data on the importance of alcohol-induced sleep disturbance to the clinical course of alcoholism (Kolla et al., 2014), there have been few studies that have specifically evaluated therapeutic agents for insomnia in animal models of protracted alcohol withdrawal (Ehlers and Slawecki, 2000, Veatch, 2006). Recently, Gabapentin which binds the a $2 \delta-1$ and -2 auxiliary subunit (Cole et al., 2005, Gee et al., 1996, Dolphin, 2013) of the voltage-gated calcium channels has been demonstrated to reduce drinking in the alcohol vapor exposure model (Roberto et al., 2008), although its effect in animal models of sleep 
physiology and waking EROs has not been previously explored. In the present study, we found that Gabapentin administration affected sleep physiology by inducing a dose dependent decrease in the latency to the first SWS episode, an increase in the duration of SWS episodes concomitant with a decrease in the number of SWS episodes (decreased sleep fragmentation). These effects were opposite to the effects of chronic alcohol exposure where increased sleep fragmentation was seen. Thus, Gabapentin has the capability to reverse several of the sleep disrupting effects of alcohol. Interestingly, Gabapentin also had a surprisingly large effect on waking EEG activity, as indexed by ERO energy, which differed depending on a history of chronic alcohol vapor exposure. Gabapentin produced an increase in theta and beta ERO energy, however, those rats with a history of chronic ethanol vapor exposure and withdrawal had a significantly blunted response to Gabapentin in ERO energy as compared to the control group. Our findings on the effect of Gabapentin on slow wave sleep support other studies in rat models (Wodarski et al., 2015) and extrapolate to findings observed in humans (Foldvary-Schaefer et al., 2002, Bazil et al., 2005) supporting its use as a potential therapeutic for sleep disruption associated with alcoholism.

Studies of the effects of Gabapentin, which binds the a $2 \delta$ auxiliary subunit of the voltagegated calcium channels, on waking and sleep EEG may also help reveal how it is involved in sleep and arousal regulation. Cole et al., (2005) have shown that several brain regions contain a high density of the $a 2 \delta$ subunits of L-type voltage-gated calcium channels (VGCCs), including areas involved in slow wave sleep regulation. The median preoptic nuclei and the lateral hypothalamic areas were found to be rich in a $2 \delta-2 \mathrm{mRNA}-1$ abeled cells. In addition, a $2 \delta-1$ and $a 2 \delta-2$ mRNAs were found to be highly expressed in the locus coeruleus and the dorsal raphe in the reticular core of the brainstem. Whereas moderate levels $a 2 \delta-1$ and $a 2 \delta-2$ mRNAs were found in the pedunculopontine nucleus. These findings are important because all these areas are important in the regulation of sleep-wake transitions and rapid eye movement (REM) sleep (Saper and Fuller, 2017).

There are also data to suggest that alcohol may influence sleep physiology through a mechanism involving these voltage-gated calcium channels. Katsura et al., (Katsura et al., 2006) have shown that sustained ethanol exposure significantly enhances the expression of a2 $\delta$-1 subunit of L-type voltage-gated calcium channels (VGCCs) in cortical neurons of mice who were exposed to ethanol vapor. Those observations further support earlier findings where prolonged exposure to ethanol ( 6 days) was found to increase depolarizationstimulated ${ }^{45} \mathrm{Ca}^{2+}$ uptake in PC12 cells in vitro (Greenberg et al., 1987), and to increase the number of dihydropyridine binding sites located on L-type calcium channels. Taken together these findings suggest that chronic ethanol exposure can increase the number of voltagedependent $\mathrm{Ca}^{2+}$ channels in neural tissues, in the rat. Additionally, Whittington and Little (1991) showed that chronic treatment with nitrendipine (a calcium channel antagonist) given concurrently with ethanol, prevented symptoms of ethanol withdrawal and also attenuated the rise in the number of central dihydropyridine binding sites, in mice (Whittington et al., 1991).

Several studies suggest that Gabapentin may also act on voltage gated calcium channels. In animal models of neuropathic pain, it has been shown that the a $2 \delta-1$ calcium subunit controls neurotransmitter release and that its up-regulation further facilitates excitatory 
transmission. Overexpression of a $2 \delta-1$ increases the frequency, but not the amplitude, of mEPSCs in the dorsal horn and that effect has been shown to be reversed by Gabapentin administration (Zhou and Luo, 2014). Therefore, it has been suggested that the $a 2 \delta-1$ subunit of the voltage-gated calcium channels is necessary for the analgesic actions of Gabapentin (Zhou and Luo, 2014). We speculate that chronic ethanol exposure may involve the upregulation of the $a 2 \delta$ subunit influencing activity-dependent calcium signaling cascades leading to the hyper-excitability seen in ethanol withdrawal, and further, that Gabapentin could reduce this hyper-excitability by acting on these pathways (Dolphin, 2016).

Although the exact mechanisms of alcohol-induced sleep disturbance remain unclear, our studies support the hypothesis that chronic ethanol exposure produces changes in sleep/wake physiology consistent with a state of neuronal hyper-excitability. We demonstrate that the changes seen in sleep/wake physiology, following chronic ethanol exposure, primarily involve a fragmentation of sleep and an increase in ERO beta frequencies. Gabapentin was found to reverse these effects but also produced a dose-dependent increase in ERO energy in the control group that was significantly larger than the ethanol-exposed group in the theta frequency bands. Taken together these studies suggest that Gabapentin can reverse some of the alcohol- induced sleep and EEG deficits but does not eliminate all of the enduring brain effects of ethanol exposure.

\section{Acknowledgments}

Source of support: This work was supported by National Institute of Health (NIH) grants, U01 AA019969; R01 AA006059 to Cindy L. Ehlers from the National Institute on Alcohol Abuse and Alcoholism (NIAAA)

This work was supported by National Institute of Health (NIH) grants, U01 AA019969; R01 AA006059 to Cindy L. Ehlers from the National Institute on Alcohol Abuse and Alcoholism (NIAAA). The authors thank Phil Lau for help in statistical analyses. James Havstad developed the software used for EEG and EROs assessments.

\section{Abbreviations}

$\begin{array}{ll}\text { ERP } & \text { Event-related potentials } \\ \text { FCTX } & \text { Frontal cortex } \\ \text { PCTX } & \text { Parietal cortex } \\ \text { SWS } & \text { slow wave sleep } \\ \text { PLI } & \text { phase locking index } \\ \text { ROI } & \text { region of interest } \\ \text { GBP } & \text { Gabapentin }\end{array}$

\section{References}

American Psychiatric Association; DSM-5 Task Force. Diagnostic and statistical manual of mental disorders: DSM-5. Washington, D.C: American Psychiatric Association; 2013.

Anokhin AP. Genetic psychophysiology: advances, problems, and future directions. Int J Psychophysiol. 2014; 93:173-97. [PubMed: 24739435] 
Basar E, Basar-Eroglu C, Karakas S, Schurmann M. Are cognitive processes manifested in eventrelated gamma, alpha, theta and delta oscillations in the EEG? Neurosci Lett. 1999; 259:165-168. [PubMed: 10025584]

Basar E, Basar-Eroglu C, Karakas S, Schurmann M. Brain oscillations in perception and memory. Int J Psychophysiol. 2000; 35:95-124. [PubMed: 10677641]

Bauer LO. Predicting relapse to alcohol and drug abuse via quantitative electroencephalography. Neuropsychopharmacology. 2001; 25:332-340. [PubMed: 11522462]

Bazil CW, Battista J, Basner RC. Gabapentin improves sleep in the presence of alcohol. J Clin Sleep Med. 2005; 1:284-287. [PubMed: 17566190]

Brower KJ. Assessment and treatment of insomnia in adult patients with alcohol use disorders. Alcohol. 2015; 49:417-427. [PubMed: 25957855]

Brower KJ, Myra Kim H, Strobbe S, Karam-Hage MA, Consens F, Zucker RA. A randomized doubleblind pilot trial of gabapentin versus placebo to treat alcohol dependence and comorbid insomnia. Alcohol Clin Exp Res. 2008; 32:1429-1438. [PubMed: 18540923]

Brower KJ, Perron BE. Prevalence and correlates of withdrawal-related insomnia among adults with alcohol dependence: results from a national survey. Am J Addict. 2010; 19:238-244. [PubMed: 20525030]

Clark CP, Gillin JC, Golshan S, De Modena A, Smith TL, Danowski S, Irwin M, Schuckit M. Increased REM sleep density at admission predicts relapse by three months in primary alcoholics with a lifetime diagnoses of secondary depression. Biol Psychiatry. 1998; 43:601-607. [PubMed: 9564445]

Cole RL, Lechner SM, Williams ME, Prodanovich P, Bleicher L, Varney MA, Gu G. Differential distribution of voltage-gated calcium channel alpha-2 delta (alpha2delta) subunit mRNAcontaining cells in the rat central nervous system and the dorsal root ganglia. J Comp Neurol. 2005; 491:246-269. [PubMed: 16134135]

Coleman PJ, Gotter AL, Herring WJ, Winrow CJ, Renger JJ. The Discovery of Suvorexant, the First Orexin Receptor Drug for Insomnia. Annu Rev Pharmacol Toxicol. 2017; 57:509-533. [PubMed: 27860547]

Conroy DA, Todd Arnedt J, Brower KJ, Strobbe S, Consens F, Hoffmann R, Armitage R. Perception of sleep in recovering alcohol-dependent patients with insomnia: relationship with future drinking. Alcohol Clin Exp Res. 2006; 30:1992-1999. [PubMed: 17117964]

Criado JR, Wills DN, Walker BM, Ehlers CL. Effects of adolescent ethanol exposure on sleep in adult rats. Alcohol. 2008; 42:631-639. [PubMed: 18922666]

Dolphin AC. The alpha2delta subunits of voltage-gated calcium channels. Biochim Biophys Acta. 2013; 1828:1541-1549. [PubMed: 23196350]

Dolphin AC. Voltage-gated calcium channels and their auxiliary subunits: physiology and pathophysiology and pharmacology. J Physiol. 2016; 594:5369-5390. [PubMed: 27273705]

Drummond SP, Gillin JC, Smith TL, De Modena A. The sleep of abstinent pure primary alcoholic patients: natural course and relationship to relapse. Alcohol Clin Exp Res. 1998; 22:1796-1802. [PubMed: 9835298]

Ehlers CL, Desikan A, Wills DN. Developmental differences in EEG and sleep responses to acute ethanol administration and its withdrawal (hangover) in adolescent and adult Wistar rats. Alcohol. 2013; 47:601-610. [PubMed: 24169089]

Ehlers CL, Desikan A, Wills DN. Event-related potential responses to the acute and chronic effects of alcohol in adolescent and adult Wistar rats. Alcohol Clin Exp Res. 2014; 38:749-759. [PubMed: 24483322]

Ehlers CL, Gilder DA, Criado JR, Caetano R. Sleep quality and alcohol-use disorders in a select population of young-adult Mexican Americans. J Stud Alcohol Drugs. 2010; 71:879-884. [PubMed: 20946745]

Ehlers CL, Slawecki CJ. Effects of chronic ethanol exposure on sleep in rats. Alcohol. 2000; 20:173179. [PubMed: 10719796]

Ehlers CL, Wills DN, Havstad J. Ethanol reduces the phase locking of neural activity in human and rodent brain. Brain Res. 2012; 1450:67-79. [PubMed: 22410292] 
Ehlers CL, Wills DN, Phillips E, Havstad J. Low voltage alpha EEG phenotype is associated with reduced amplitudes of alpha event-related oscillations, increased cortical phase synchrony, and a low level of response to alcohol. Int J Psychophysiol. 2015; 98:65-75. [PubMed: 26151497]

Fein G, Allen J. EEG spectral changes in treatment-naive, actively drinking alcoholics. Alcohol Clin Exp Res. 2005; 29:538-546. [PubMed: 15834218]

Foldvary-Schaefer N, De Leon Sanchez I, Karafa M, Mascha E, Dinner D, Morris HH. Gabapentin increases slow-wave sleep in normal adults. Epilepsia. 2002; 43:1493-1497. [PubMed: 12460250]

Gee NS, Brown JP, Dissanayake VU, Offord J, Thurlow R, Woodruff GN. The novel anticonvulsant drug, gabapentin (Neurontin), binds to the alpha2delta subunit of a calcium channel. J Biol Chem. 1996; 271:5768-5776. [PubMed: 8621444]

Greenberg DA, Carpenter CL, Messing RO. Ethanol-induced component of 45Ca2+ uptake in PC12 cells is sensitive to Ca2+ channel modulating drugs. Brain Res. 1987; 410:143-146. [PubMed: 2438011]

Irwin M, Miller C, Gillin JC, De Modena A, Ehlers CL. Polysomnographic and spectral sleep EEG in primary alcoholics: an interaction between alcohol dependence and African-American ethnicity. Alcohol Clin Exp Res. 2000; 24:1376-1384. [PubMed: 11003203]

Katsura M, Shibasaki M, Hayashida S, Torigoe F, Tsujimura A, Ohkuma S. Increase in expression of alpha1 and alpha2/delta1 subunits of L-type high voltage-gated calcium channels after sustained ethanol exposure in cerebral cortical neurons. J Pharmacol Sci. 2006; 102:221-230. [PubMed: 17031067]

Klimesch W, Sauseng P, Hanslmayr S, Gruber W, Freunberger R. Event-related phase reorganization may explain evoked neural dynamics. Neurosci Biobehav Rev. 2007; 31:1003-1016. [PubMed: 17532471]

Kolla BP, Schneekloth T, Biernacka J, Mansukhani M, Geske J, Karpyak V, Hall-Flavin D, Louikianova L, Frye MA. The course of sleep disturbances in early alcohol recovery: an observational cohort study. Am J Addict. 2014; 23:21-26. [PubMed: 24313237]

Lo HS, Yang CM, Lo HG, Lee CY, Ting H, Tzang BS. Treatment effects of gabapentin for primary insomnia. Clin Neuropharmacol. 2010; 33:84-90. [PubMed: 20124884]

Magnus L. Nonepileptic uses of gabapentin. Epilepsia. 1999; 40(Suppl 6):S66-72. discussion S73-64. [PubMed: 10530686]

Mark TL, Kassed CA, Vandivort-Warren R, Levit KR, Kranzler HR. Alcohol and opioid dependence medications: prescription trends, overall and by physician specialty. Drug Alcohol Depend. 2009; 99:345-349. [PubMed: 18819759]

Mason BJ, Quello S, Goodell V, Shadan F, Kyle M, Begovic A. Gabapentin treatment for alcohol dependence: a randomized clinical trial. JAMA Intern Med. 2014; 174:70-77. [PubMed: 24190578]

Meyers JL, Zhang J, Wang JC, Su J, Kuo SI, Kapoor M, Wetherill L, Bertelsen S, Lai D, Salvatore JE, Kamarajan C, Chorlian D, Agrawal A, Almasy L, Bauer L, Bucholz KK, Chan G, Hesselbrock V, Koganti L, Kramer J, Kuperman S, Manz N, Pandey A, Seay M, Scott D, Taylor RE, Dick DM, Edenberg HJ, Goate A, Foroud T, Porjesz B. An endophenotype approach to the genetics of alcohol dependence: a genome wide association study of fast beta EEG in families of African ancestry. Mol Psychiatry. 2017

Pandey AK, Kamarajan C, Rangaswamy M, Porjesz B. Event-Related Oscillations in Alcoholism Research: A Review. J Addict Res Ther Suppl. 2012:7.

Paxinos, G., Watson, C. The rat brain in stereotaxic coordinates. 2. Academic Press; Sydney, Australia: 1986.

Porjesz B, Almasy L, Edenberg HJ, Wang K, Chorlian DB, Foroud T, Goate A, Rice JP, O'Connor SJ, Rohrbaugh J, Kuperman S, Bauer LO, Crowe RR, Schuckit MA, Hesselbrock V, Conneally PM, Tischfield JA, Li TK, Reich T, Begleiter H. Linkage disequilibrium between the beta frequency of the human EEG and a GABAA receptor gene locus. Proc Natl Acad Sci U S A. 2002; 99:37293733. [PubMed: 11891318]

Porjesz B, Rangaswamy M, Kamarajan C, Jones KA, Padmanabhapillai A, Begleiter H. The utility of neurophysiological markers in the study of alcoholism. Clin Neuropathol. 2005; 116:993-1018. 
Qaseem A, Kansagara D, Forciea MA, Cooke M, Denberg TD. Clinical Guidelines Committee of the American College of P. Management of Chronic Insomnia Disorder in Adults: A Clinical Practice Guideline From the American College of Physicians. Ann Intern Med. 2016; 165:125-133. [PubMed: 27136449]

Rangaswamy M, Porjesz B. Understanding alcohol use disorders with neuroelectrophysiology. Handb Clin Neurol. 2014; 125:383-414. [PubMed: 25307587]

Rangaswamy M, Porjesz B, Chorlian DB, Wang K, Jones KA, Bauer LO, Rohrbaugh J, O'Connor SJ, Kuperman S, Reich T, Begleiter H. Beta power in the EEG of alcoholics. Biol Psychiatry. 2002; 52:831-842. [PubMed: 12372655]

Roach BJ, Mathalon DH. Event-related EEG time-frequency analysis: an overview of measures and an analysis of early gamma band phase locking in schizophrenia. Schizophr Bull. 2008; 34:907-926. [PubMed: 18684772]

Roberto M, Gilpin NW, O’Dell LE, Cruz MT, Morse AC, Siggins GR, Koob GF. Cellular and behavioral interactions of gabapentin with alcohol dependence. J Neurosci. 2008; 28:5762-5771. [PubMed: 18509038]

SAMHSA. Substance Abuse and Mental Health Services Administration. Center for Behavioral Health Statistics and Quality. [Accessed Aug 2017] National Survey on Drug Use and Health, 2014 and 2015. [Online]. Available: https://www.samhsa.gov/data/sites/default/files/NSDUH-DetTabs-2015/ NSDUH-DetTabs-2015/NSDUH-DetTabs-2015.htm-tab5-6a

Saper CB, Fuller PM. Wake-sleep circuitry: an overview. Curr Opin Neurobiol. 2017; 44:186-192. [PubMed: 28577468]

Sateia MJ, Buysse DJ, Krystal AD, Neubauer DN, Heald JL. Clinical Practice Guideline for the Pharmacologic Treatment of Chronic Insomnia in Adults: An American Academy of Sleep Medicine Clinical Practice Guideline. J Clin Sleep Med. 2017; 13:307-349. [PubMed: 27998379]

Schack B, Klimesch W. Frequency characteristics of evoked and oscillatory electroencephalic activity in a human memory scanning task. Neurosci Lett. 2002; 331:107-110. [PubMed: 12361852]

Slawecki CJ. Altered EEG responses to ethanol in adult rats exposed to ethanol during adolescence. Alcohol Clin Exp Res. 2002; 26:246-254. [PubMed: 11964565]

Stockwell RG, Mansinha L, Lowe RP. Localization of the complex spectrum: The S Transform. IEEE Trans on Signal Processing. 1996; 44:998-1001.

Thakkar MM, Sharma R, Sahota P. Alcohol disrupts sleep homeostasis. Alcohol. 2015; 49:299-310. [PubMed: 25499829]

Thatcher RW. Coherence, phase differences, phase shift, and phase lock in EEG/ERP analyses. Dev Neuropsychol. 2012; 37:476-496. [PubMed: 22889341]

Veatch LM. Disruptions in sleep time and sleep architecture in a mouse model of repeated ethanol withdrawal. Alcohol Clin Exp Res. 2006; 30:1214-1222. [PubMed: 16792570]

Walker BM, Drimmer DA, Walker JL, Liu T, Mathe AA, Ehlers CL. Effects of prolonged ethanol vapor exposure on forced swim behavior, and neuropeptide $\mathrm{Y}$ and corticotropin-releasing factor levels in rat brains. Alcohol. 2010; 44:487-493. [PubMed: 20705420]

Whittington MA, Dolin SJ, Patch TL, Siarey RJ, Butterworth AR, Little HJ. Chronic dihydropyridine treatment can reverse the behavioural consequences of and prevent adaptations to, chronic ethanol treatment. Br J Pharmacol. 1991; 103:1669-1676. [PubMed: 1834295]

Whittington MA, Little HJ. Nitrendipine, given during drinking, decreases the electrophysiological changes in the isolated hippocampal slice, seen during ethanol withdrawal. Br J Pharmacol. 1991; 103:1677-1684. [PubMed: 1933131]

Wodarski R, Schuh-Hofer S, Yurek DA, Wafford KA, Gilmour G, Treede RD, Kennedy JD. Development and pharmacological characterization of a model of sleep disruption-induced hypersensitivity in the rat. Eur J Pain. 2015; 19:554-566. [PubMed: 25195796]

Zhou C, Luo ZD. Electrophysiological characterization of spinal neuron sensitization by elevated calcium channel alpha-2-delta-1 subunit protein. Eur J Pain. 2014; 18:649-658. [PubMed: 24151064] 


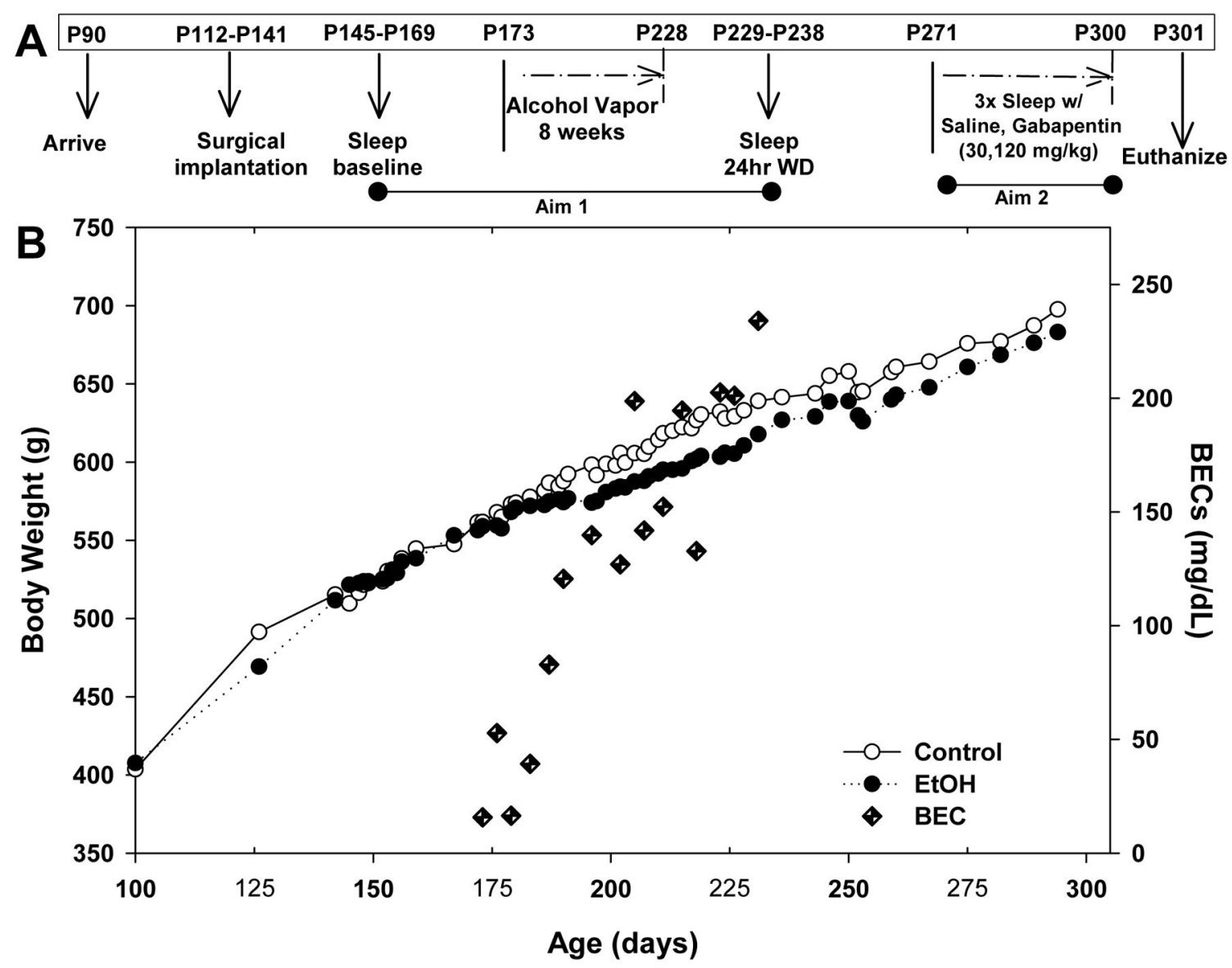

Figure 1.

Time line of the experimental design. A) Graphical representation of the timing of the experimental procedure, B) Animals' body weights shown for ethanol and control groups, with the average BECs in the ethanol exposed rats. Average BEC for the 8 weeks was 128.2 $\pm 17.4 \mathrm{mg} / \mathrm{dL}$. 


\section{Latency to SWS}

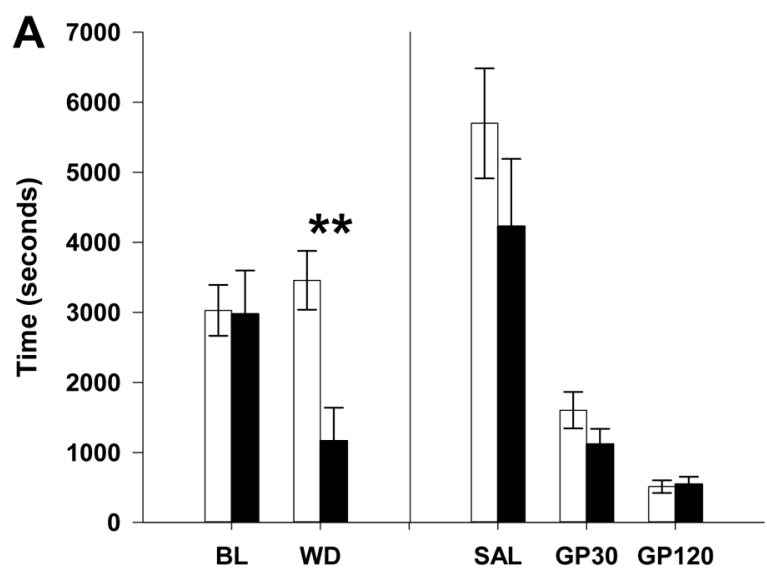

Number of SWS Episodes

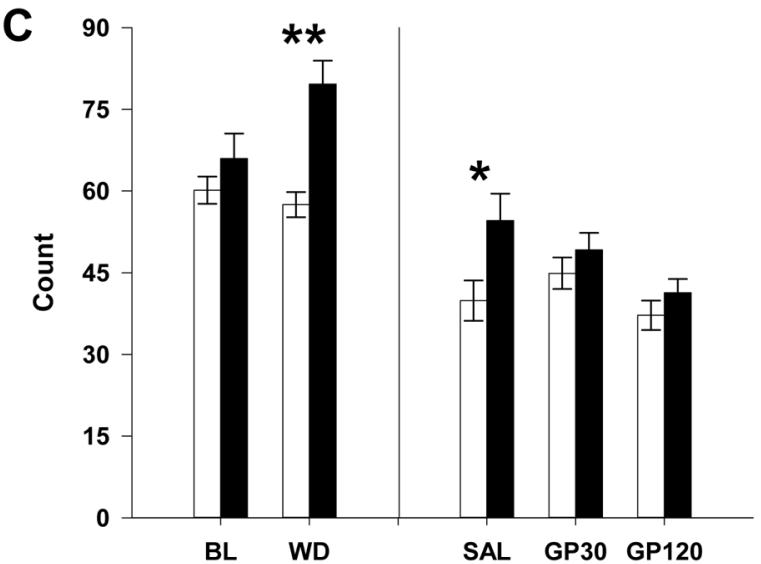

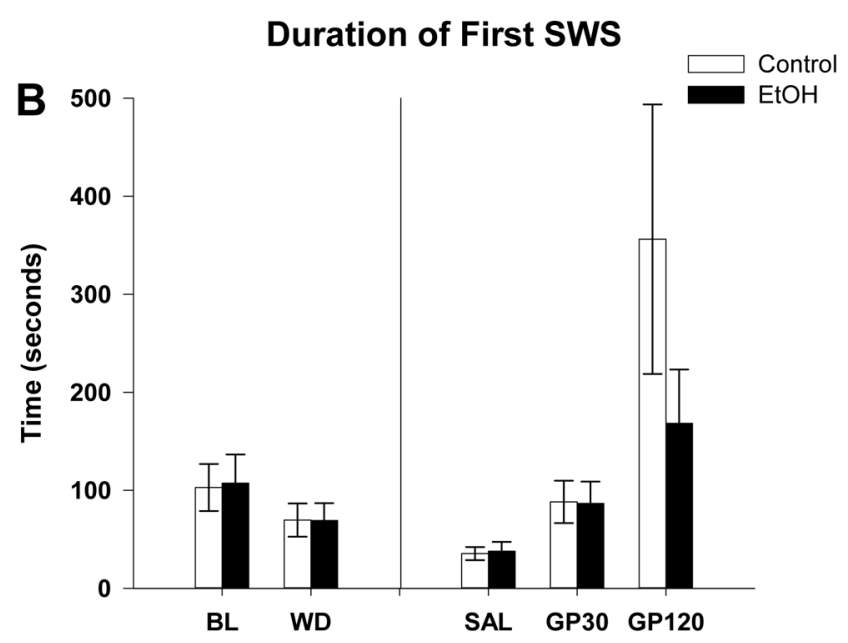

Mean SWS Episode Duration

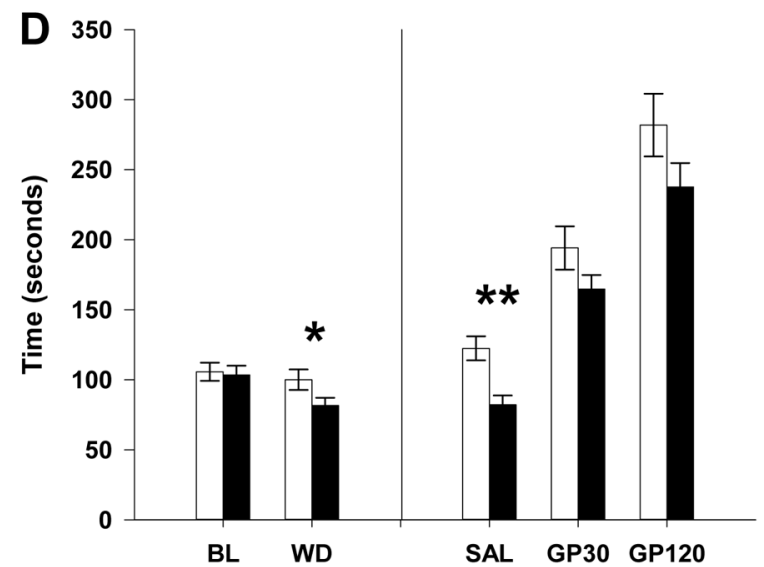

Figure 2.

Effects of vapor exposure on slow wave sleep (SWS) measures and effect of saline and Gabapentin (GP). Mean values and significant statistics from post hoc ANOVA for A) Latency to SWS, B) Duration of first SWS, C) Number of SWS states and D) Mean duration of SWS. ANOVA showed that in alcohol withdrawal latency to first SWS decreased (A) while SWS became fragmented with a significant increase in the number of SWS episodes (C) but a significant decrease in the mean duration of each episode (D). Gabapentin caused a dose dependent decrease in the latency to the first SWS episode (A) and an increase in the duration of the first SWS episodes (B). Additionally, Gabapentin ameliorated significant differences between vapor exposed and control animals with a dose dependent decrease in the number of SWS episodes (C) and an increase in the mean duration SWS episodes (D). * indicates $\mathrm{p}<0.05$ ethanol effect compared to control. $* *$ indicates $\mathrm{p}<0.01 \mathrm{EtOH}$ effect to control. Error bars = SEM. 
FCTX
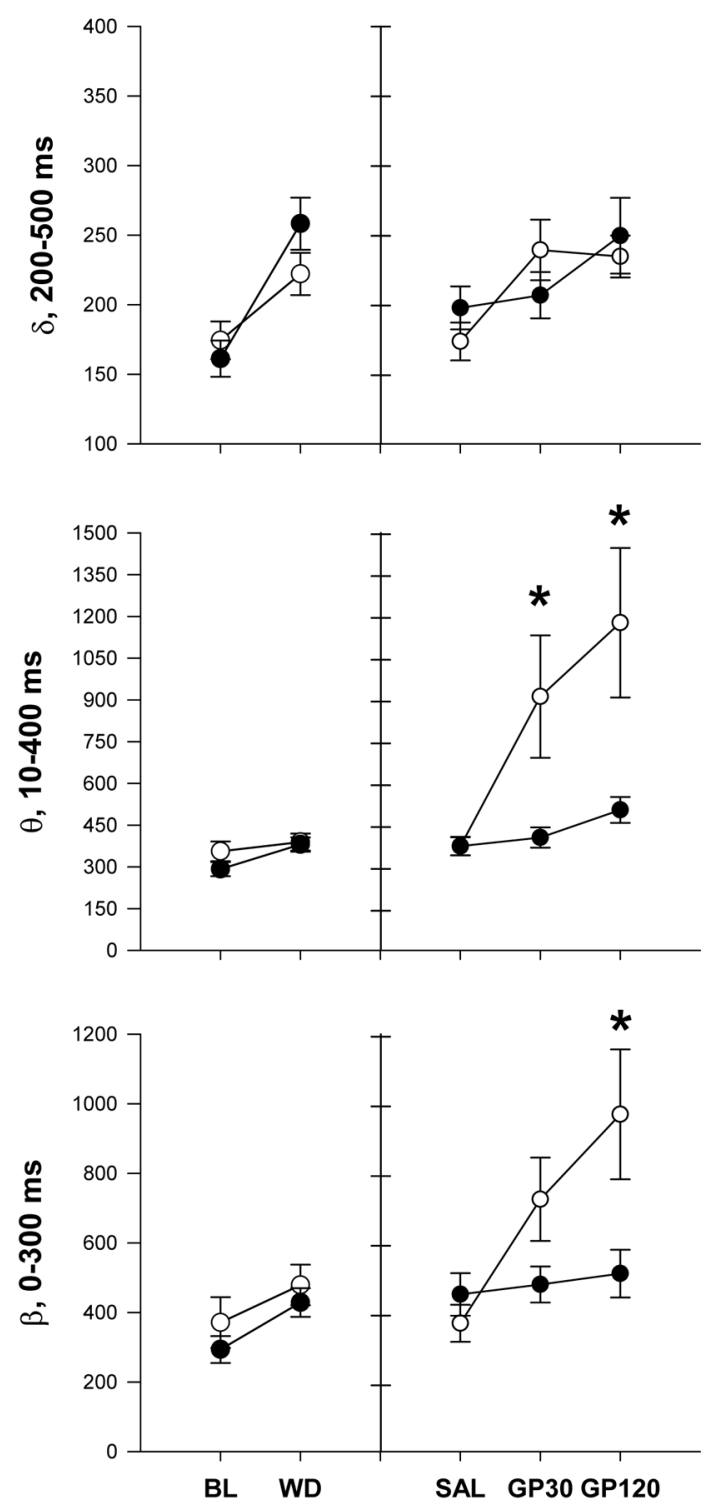

PCTX
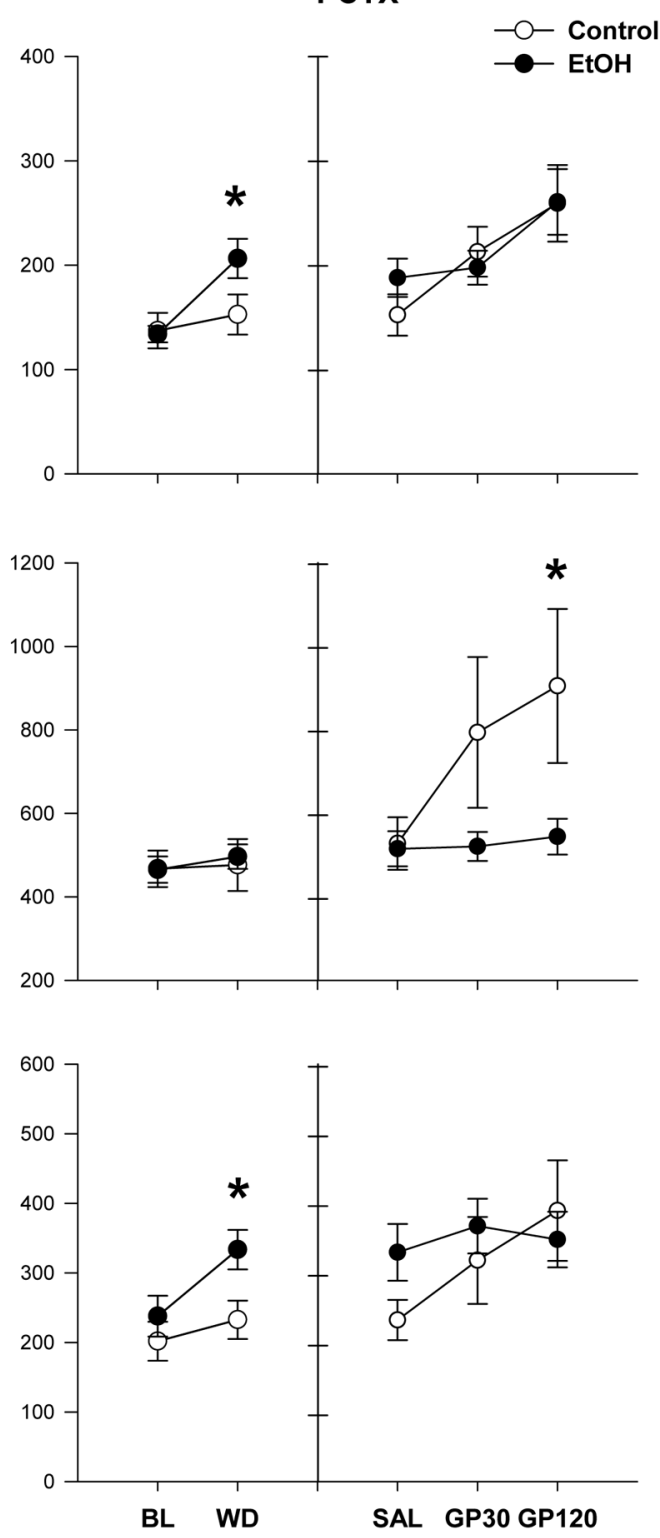

Figure 3.

Effects of chronic ethanol exposure and withdrawal, and saline and Gabapentin on eventrelated oscillation (ERO) energy. ANOVA showed that during withdrawal chronic ethanol exposure increased ERO energy in delta and beta frequency bands in parietal cortex; Gabapentin induced dose dependent increases in EROs energy in all bands for both brain regions with controls having significantly higher response compared to vapor exposed animals in theta and beta frequency bands in frontal cortex and in theta frequency band in the parietal cortex. $*$ indicates $\mathrm{p}<0.05$ ethanol effect compared to control. Error bars $=$ SEM. 